\title{
Five year prospective study of plasma renin activity and blood pressure in patients with longstanding reflux nephropathy
}

\author{
J M SAVAGE, C T KOH, V SHAH, T M BARRATT, AND M J DILLON \\ Department of Paediatric Nephrology, Institute of Child Health and the Renal Unit, Hospital for Sick \\ Children, Great Ormond Street, London
}

SUMMARY Eight of 100 normotensive children who had pyelonephritic scarring secondary to urinary infection and vesicoureteric reflux were found in an earlier study to have increased plasma renin activity (PRA). Because the risk of these patients becoming hypertensive is between $10 \%$ and $20 \%$ and because renin activity may play a part in the pathogenesis of the hypertension, PRA and blood pressure were studied in 98 of the original group after five years of follow up. Two patients could not be traced, and other factors that might influence blood pressure or PRA led us to exclude 13 others, 10 of whom were girls taking oral hormonal contraceptives.

Increased PRA was found in 11 of the remaining 85 patients but not in five of the eight patients with increased PRA in the first study. Of eight children identified as hypertensive in the follow up study, only three had had increased PRA five years previously.

In normal children PRA decreases with age. In the initial study this tendency was less pronounced in children with renal scars, and in the follow up study it was reversed. This was also confirmed by PRA standard deviation scores, which showed a significant increase in PRA during the five years. PRA tends to rise in patients with pyelonephritic scars as they grow older.

There was no direct correlation between blood pressure and PRA, plasma creatinine concentration, or degree of scarring. Analysis of blood pressure standard deviation scores, however, suggested an excessive rise in blood pressure during the five years.

Pyelonephritic scarring is a major cause of sustained hypertension in childhood..$^{1-3}$ This type of renal scar is produced by ascending urinary tract infection in the presence of vesicoureteric reflux early in childhood and has been called reflux nephropathy. ${ }^{4-6}$ Once scarring is present in a child's kidney there is at least a $10 \%$ risk of subsequent hypertension. ${ }^{78}$ Furthermore, there is an association between such hypertension and later deterioration in renal function. Early detection and treatment of hypertension in these patients are therefore important because of the high risk of morbidity and mortality. ${ }^{9}$

The aetiology of the hypertension has been difficult to establish because it is a late sequel of the scarring. ${ }^{810}$ The renin-angiotensin system has been implicated, ${ }^{11} 12$ and we previously showed that plasma renin activity (PRA) is often increased in children with renal scars. ${ }^{13}{ }^{14}$ In 1978 we measured PRA in 100 normotensive children known to have renal scars and vesicoureteric reflux. ${ }^{13}$ Eight had increased PRA (Fig. 1), and the natural tendency of PRA to fall with age was less pronounced than in normal controls (Fig. 2). That initial study supported the hypothesis that in children with scarred kidneys the renin-angiotensin system was over active and increased PRA might precede a rise in blood pressure. The present follow up study was done to reassess the relation between PRA and blood pressure in the same children after five years and to find out whether PRA predicts subsequent hypertension.

\section{Patients and methods}

One hundred children with renal scarring visible in $x$-ray pictures and vesicoureteric reflux that had been corrected surgically were studied in 1978; for this study we traced 98 of these patients. Initially 


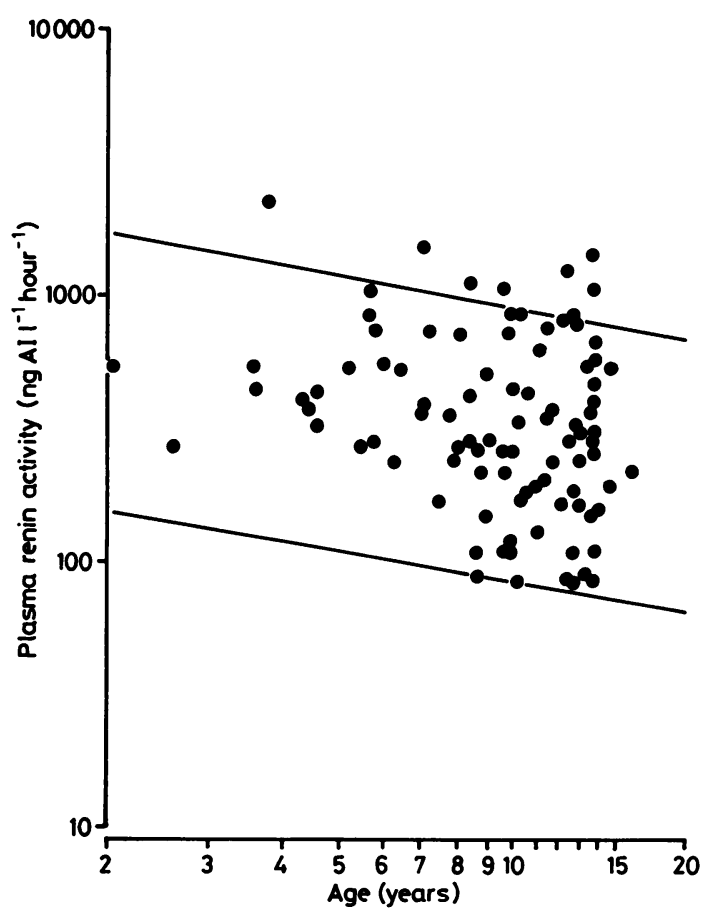

Fig. 1 PRA in normotensive children with scarred kidneys in 1978 (Traditional units to SI angiotensin I: $1297 \mathrm{ng} / \mathrm{l}=1$ nmol/l).

these children had normal plasma creatinine concentrations and blood pressure. New factors likely to influence blood pressure or PRA were sought, and, although all patients were investigated, only 85 are included in this study: 13 patients were excluded because they were taking a hormonal contraceptive pill $(n=10)$, were pregnant $(n=1)$, had had a nephrectomy $(n=1)$, or had died $(n=1)$. Thus 36 male patients aged 7-21 years and 49 female patients aged 6-20 years were followed up.

The degree of renal scarring was reassessed from the most recent $x$-ray pictures available and scored as in the original study-that is, normal kidney $=0$, single small polar scar $=1$, complete polar destruction $=2$, loss of both renal poles or a small shrunken kidney $=3$. Scarring had increased in two patients, but this may have been due to a change in the imaging method used, from intravenous urography to scanning with dimercaptosuccinic acid labelled with technetium- $99 \mathrm{~m}$. Neither patient had increased blood pressure or PRA.

Each child was asked to attend hospital, where blood pressure was measured in the supine and erect positions with a Dinamapp Vital Signs Monitor with an automatic tracer designed to eliminate observer

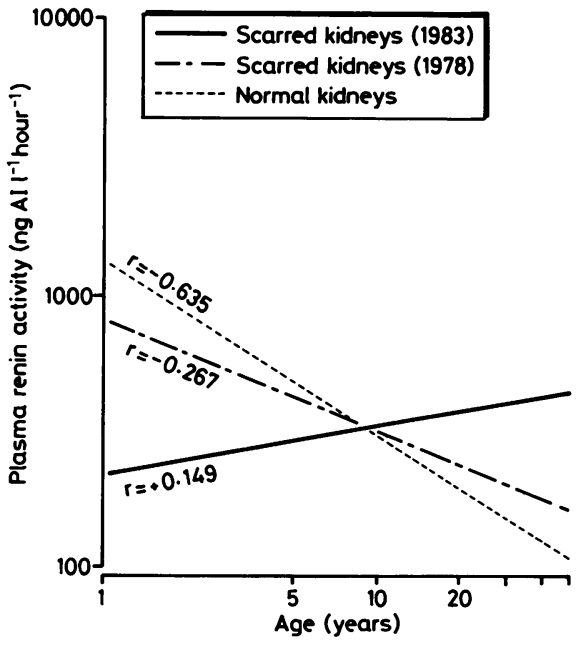

Fig. 2 Regression of PRA with age for children with normal kidneys and those with scarring in 1978 and 1983 (Traditional units to SI angiotensin I: $1297 \mathrm{ng} / \mathrm{l}=1 \mathrm{nmol} / \mathrm{l}$ ).

bias. A $1 \mathrm{ml}$ sample of blood was taken from the patients after they had rested supine for two hours. PRA was estimated with a semimicro radioimmunoassay ${ }^{15}$ and plasma creatinine concentration by the Jaffe reaction with an autoanalyser. Because of the difficulty of comparing sodium excretion rates in children of different sizes, a urinary sodium: creatinine ratio was used as a convenient approximation. A urine sample was therefore obtained from each child, and mean sodium excretion was calculated from the sodium:creatinine ratio, assuming normal daily creatinine excretion to be constant at $132 \mathrm{mmol} / \mathrm{kg}$ body weight $/ 24 \mathrm{~h}$ : mean sodium excretion $=$ urine sodium concentration/urine creatinine concentration.

\section{Results}

In this follow up study PRA was increased in 11 $(13 \%)$ of the 85 patients studied (Fig. 3). In the initial study eight of the 100 children had had increased PRA, but only three children showed high activity in both studies.

In the 85 children followed up there was a positive correlation of PRA with age $(r=+0 \cdot 1486)$, the opposite of the negative correlation described in normal children $(\mathrm{r}=-0 \cdot 635)$. In our original study we showed that in children with scarred kidneys this normal negative correlation was weakened $(\mathrm{r}=-0.267)^{13}$; after five years it was reversed (Fig. 2).

So that we could compare PRA in the children studied in 1978 and 1983 standard deviation scores 


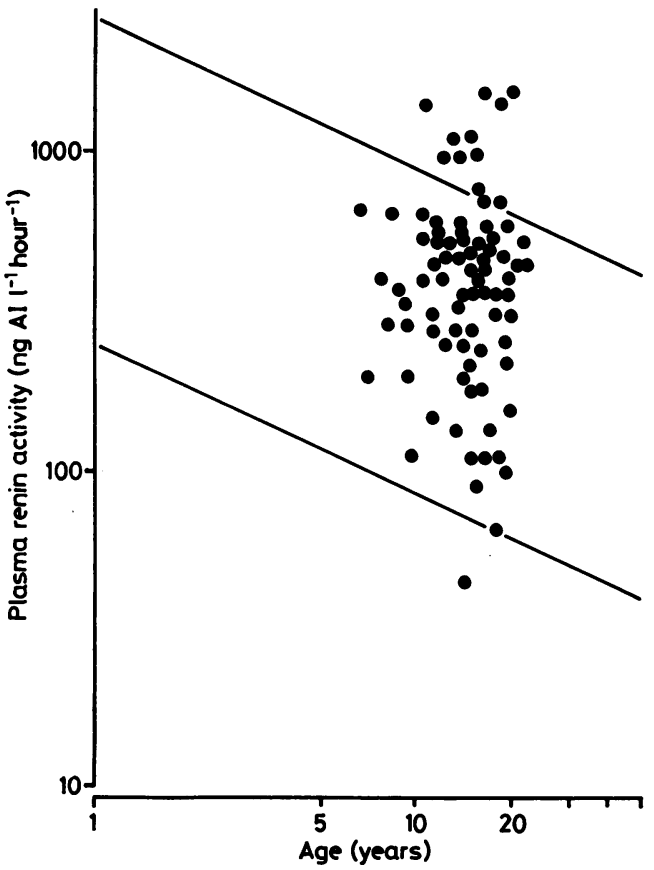

Fig. 3 PRA in children with scarred kidneys after five years in 1983 (Traditional units to SI angiotensin I: 1297 ng/l=1 nmol/l).

were calculated and compared with paired Student's $t$ test. There was a significant increase $(p<0.001)$ in the standard deviation scores between the initial study and the follow up study (Table 1).

In the follow up study we found no significant relation between PRA and mean sodium excretion, plasma creatinine concentration, or the degree of renal scarring (Table 2). There was no difference in mean sodium excretion between the children studied and a group of healthy children evaluated to establish normal values for PRA. Of the 11 patients with abnormally increased PRA, none had a raised plasma creatinine concentration, whereas five of the remaining 74 subjects did. The degrees of scarring in

Table 1 Comparison of PRA and blood pressure measurements taken five years apart in 85 patients with renal scarring

\begin{tabular}{llll}
\hline Measurement & $\begin{array}{l}\text { Statistical } \\
\text { method }\end{array}$ & $p$ value & Conclusion \\
\hline PRA & $\begin{array}{c}\text { Paired } t \text { test } \\
\text { on SD scores }\end{array}$ & $<0.001$ & $\begin{array}{c}\text { Highly significant } \\
\text { increase }\end{array}$ \\
$\begin{array}{l}\text { Diastolic blood } \\
\text { pressure } \\
\begin{array}{c}\text { Systolic blood } t \text { test } \\
\text { pressure }\end{array}\end{array}$ & $\begin{array}{c}\text { on SD scores } \\
\text { Paired } t \text { test } \\
\text { on SD scores }\end{array}$ & $<0.001$ & $\begin{array}{c}\text { increase } \\
\text { Significant } \\
\text { increase }\end{array}$ \\
\hline
\end{tabular}

Table 2 Details of patients with raised PRA at five year follow up

\begin{tabular}{|c|c|c|c|c|}
\hline \multicolumn{2}{|c|}{$\begin{array}{l}\text { PRA ng Al } l^{-1} h^{-l} \\
\left.\text { (nmol Al } l^{-l} L^{-l}\right)\end{array}$} & \multirow[t]{2}{*}{$\begin{array}{l}\text { Degree of } \\
\text { scarring }\end{array}$} & \multirow{2}{*}{$\begin{array}{l}\text { Plasma } \\
\text { creatinine } \\
\text { ( } \mu \text { mol/ll) }\end{array}$} & \multirow[t]{2}{*}{$\begin{array}{l}\text { Age } \\
\text { (years) }\end{array}$} \\
\hline $\begin{array}{l}\text { Patients } \\
\text { values }\end{array}$ & $\begin{array}{l}\text { Upper limit } \\
\text { of normal }\end{array}$ & & & \\
\hline $1338(1 \cdot 03)$ & $880(0 \cdot 67)$ & 6 & 74 & $10 \cdot 7$ \\
\hline $943(0.73)$ & $790(0 \cdot 60)$ & 2 & 44 & $12 \cdot 3$ \\
\hline $965(0.74)$ & $770(0.59)$ & 4 & 74 & $13 \cdot 5$ \\
\hline $1075(0.83)$ & $770(0.59)$ & 2 & 64 & $13 \cdot 6$ \\
\hline $1009(0-78)$ & $750(0.58)$ & 5 & 87 & 14.9 \\
\hline $746(0.58)$ & $746(0.57)$ & 4 & 77 & $15 \cdot 4$ \\
\hline $965(0.74)$ & $725(0.55)$ & 4 & 44 & $15 \cdot 8$ \\
\hline $1491(1 \cdot 15)$ & $710(0 \cdot 54)$ & 2 & 83 & $16 \cdot 2$ \\
\hline $690(0 \cdot 53)$ & $680(0.52)$ & 2 & 57 & $17 \cdot 7$ \\
\hline $1404(1.08)$ & $670(0 \cdot 51)$ & 5 & 87 & $18 \cdot 3$ \\
\hline $1491(1 \cdot 15)$ & $660(0.50)$ & 2 & 68 & $19 \cdot 5$ \\
\hline
\end{tabular}

Values given as traditional (SI) units.

the 11 children scored between 2 and 6 on the scoring system described (Table 2).

Hypertensive patients were excluded from the initial study. At follow up blood pressure was above the 95th centile in three, none of whom had increased PRA. A further four patients had borderline increases in blood pressure at the 90th centile for their ages. Three of these four had had increased PRA during the initial study, but in only one was the activity high after five years. Centiles of blood pressure were based on American Task Force figures. ${ }^{16}$

As for PRA, standard deviation scores were calculated for both systolic and diastolic blood pressures and the scores in 1978 and 1983 compared. The difference between systolic blood pressure scores was significant $(p<0.05)$, but there was a more obvious difference in those for diastolic blood pressure $(p<0.001)($ Table 1$)$. There was no significant correlation between blood pressure and PRA, plasma creatinine concentration, or degree of scarring (Spearman's rank correlation test). These findings are similar to those of the previous study.

Two subjects had increased PRA in both studies, and their blood pressure lay well within the normal range on both occasions. The one patient who died between the two studies had hypertensive encephalopathy; he had normal blood pressure and PRA but grade 5 renal scarring in the initial study.

\section{Discussion}

The hypothesis that renin plays a major part in the hypertension associated with pyelonephritic renal scarring was supported by our earlier observation of a high incidence of increased PRA in children in whom both were found. ${ }^{1314}$ When we detected increased PRA in eight of 100 normotensive chil- 
dren with renal scars we postulated that this increase in PRA might predate, and so predict, the development of hypertension in these patients. The risk of subsequent hypertension has been estimated as being between $10 \%$ and $20 \%,{ }^{8}$ and there is often a long delay between scarring and an obvious rise in blood pressure. We therefore followed up these children as they grew up. After five years four of the original patients were seriously hypertensive and four others had borderline hypertension, contirming that we identified an abnormal population because 11 hypertensive children were excluded from the initial study.

The follow up data at five years do not confirm that a single random measurement of PRA can detect abnormal PRA sufficient to predict the risk of hypertension. Only three of eight children with increased PRA initially had increased PRA at five year follow up; one of these was hypertensive. Eight children with increased PRA at follow up had had normal PRA when first studied. Thus the number of patients with high PRA increased to a total of 16 , confirming that pyelonephritic patients are likely to develop increased PRA.

The comparison of standard deviation scores for PRA between the children studied in 1978 and those studied in 1983 confirm that there was a significant increase in the scores during the five years. This observation, coupled with the development of a positive correlation between PRA and age during the five years in our patients with renal scarring, is particularly important. These findings confirm that the normal tendency of PRA to fall with age is reversed; they also confirm the role of renin in pyelonephritic hypertension and may explain the delay in onset.

It seems, however, that PRA does not necessarily lie above the normal range in all patients at risk of hypertension and that the activity may fluctuate even under standardised conditions in individual patients. This may be explained by the second pressor effect of angiotensin described by Dickinson and Lawrence. ${ }^{17}$ They showed in animal studies that angiotensin II given in doses too small to produce an appreciable rise in blood pressure, when given by single injection, can cause sustained hypertension when given as a prolonged infusion. A similar mechanism may cause hypertension in those subjects who become hypertensive despite having apparently normal PRA. Their PRA may be higher than it was before the kidneys were damaged, so producing this second pressor effect. The effect of PRA on blood pressure is most obvious when the activity is consistently above the normal range for age, but we suggest that hypertension may also be caused over a long time span by smaller or fluctuat- ing increases. Repeated measurements of PRA and a longer period of study are required to evaluate this hypothesis.

Measuring PRA under different conditions-for example, with the patient standing or when sodium is repleted-might accentuate changes in individual patients. Because it would be difficult to standardise conditions of sampling we used only samples taken from supine, unstimulated patients.

Several factors probably interact with renin in individual patients to determine their blood pressure. For example, those whose blood pressure is naturally high are most at risk of a cumulative effect. We found that the blood pressure standard deviation scores, both for systolic and diastolic pressures, increased during the five year follow up. This points to a greater increase in blood pressure in this group of patients than might be expected with time, which may be related to the underlying renal disease and renin activity.

The amount of damage to the kidneys may not be completely shown by radiological examination. When renal tissue is lost a hyperfiltration phenomenon ${ }^{18}{ }^{19}$ in the remaining nephrons may lead to deteriorating function, and a local immunological reaction to scarred tissue may have a similar effect. If these factors were relevant an important association between blood pressure and the degree of scarring or the incidence of proteinuria might be expected. We did not identify such associations, but a further prospective study is planned.

The oral contraceptive pill affects the reninangiotensin system. ${ }^{20}$ Of 10 patients taking the pill (Table 3), three had increased PRA; all these girls were excluded from our analysis. The hypertensive risk from renal scarring and from taking oestrogen is probably cumulative, and the pill may not be the ideal method of contraception for patients with chronic pyelonephritis.

This prospective study of subjects with reflux nephropathy confirms that the renin-angiotensin

Table $3 P R A$ in patients taking oral contraceptives

\begin{tabular}{lcl}
\hline $\begin{array}{l}\text { Age of patient } \\
\text { (years) }\end{array}$ & $\begin{array}{l}\text { PRA ng Al } l^{-1} L^{-1} \\
\left(n m o l ~ A l l^{-l} L^{-I}\right.\end{array}$ & $\begin{array}{l}\text { Upper limit of } \\
\text { normal for age }\end{array}$ \\
\hline $16 \cdot 7$ & $110(0 \cdot 08)$ & $700(0 \cdot 54)$ \\
$16 \cdot 9$ & $439(0 \cdot 33)$ & $700(0 \cdot 54)$ \\
$17 \cdot 2$ & $768(0 \cdot 59)$ & $690(0 \cdot 53)$ \\
$18 \cdot 36$ & $241(0 \cdot 18)$ & $670(0 \cdot 52)$ \\
$18 \cdot 76$ & $439(0 \cdot 33)$ & $670(0 \cdot 52)$ \\
$18 \cdot 8$ & $1513^{*}(1 \cdot 16)$ & $670(0 \cdot 52)$ \\
$19 \cdot 1$ & $329(0 \cdot 25)$ & $660(0 \cdot 51)$ \\
$19 \cdot 3$ & $176(0 \cdot 13)$ & $660(0 \cdot 51)$ \\
$19 \cdot 43$ & $285(0 \cdot 21)$ & $660(0 \cdot 51)$ \\
$20 \cdot 0$ & $877^{*}(0 \cdot 67)$ & $650(0 \cdot 50)$ \\
\hline
\end{tabular}

*Abnormally high for age. 
system is disturbed after renal scarring. This is most dramatically shown by the reversal of the natural tendency of PRA to fall with age and by a significant increase in PRA standard deviation scores during the five years of follow up. These were paralleled by an increase in the blood pressure standard deviation scores during the same period. We propose to continue the longitudinal follow up to determine the total incidence of hypertension and to evaluate other factors that may be operating in hypertensive patients in whom the renin-angiotensin system seems normal. Further study may also identify the factors that have a role in the deterioration in renal function and may explain the influence of oral contraceptives on blood pressure in these subjects.

We thank the Kidney Research Aid Fund and the Buttle Trust for financial support. MJD held the Geoffrey Holt award from the British Medical Association.

\section{References}

1 Still JL, Cottom D. Severe hypertension in childhood. Arch Dis Child 1967;42:34-9.

${ }^{2}$ Londe S. Causes of hypertension in the young. Pediatr Clin North Am 1978;25:55-65.

3 Gill DG, De Costa DM, Cameron JS, et al. Analysis of 100 children with severe and persistent hypertension. Arch Dis Child 1976;51:951-56.

4 Hodson CJ, Edwards D. Chronic pyelonephritis and vesicoureteric reflux. Clin Radiol 1960;11:219-31.

5 Anonymous. V.U.R.+I.R.R. =C.P.N.? [Editorial] Lancet 1974;ii:1120-1.

" Smellic JM, Normand ICS, Datz, G. Children with urinary infection: a comparison of those with and without vesicoureteric reflux. Kidney Int 1981:20:717-22.

${ }^{7}$ Holland NH, Kotchen T, Bhathena D. Hypertension in children with chronic pyclonephritis. Kidney Int 1975;8(suppl):243-51.
${ }^{8}$ Wallace DMA, Rothwell DL, Williams DI. The long-term follow-up of surgically treated vesicoureteric reflux. $\mathrm{Br} \mathrm{J} \mathrm{Urol}$ 1978;50:479-84.

9 Dillon MJ. Modern management of hypertension. In: Meadow R, ed. Recent advances in paediatrics 7. Edinburgh: Churchill Livingstone, 1984;35-55.

10) Heale WF. Hypertension and reflux nephropathy. Aust Paedtr J 1977;13:56.

"Seigler RL. Renin dependent hypertension in children with reflux nephropathy. Urology 1976;7:474-8.

12 Holland NH. Reflux nephropathy and hypertension. In: Hodson J, Kincaid Smith P. eds. Reflux nephropathy. New York: Mason Publishing, 1979;257-68.

13 Savage JM, Dillon MJ, Shah V, et al. Renin and blood pressure in children with renal scarring and vesico ureteric reflux. Lancet 1978;ii:441-4.

${ }^{14}$ Dillon MJ, Smellie JM. Peripheral plasma renin activity, hypertension and renal scarring in children. In: Hodson CJ, Heptinstall RH, Winberg J, eds. Contributions to nephrology. Reflux nephropathy update, 1983. Basle: Karger, 1983;68-80.

15 Dillon MJ. Ryness J. Measurement of plasma renin activity by semi-micro radioimmunoassay of generated angiotensin I. J Clin Pathol 1975;28:625-30.

${ }^{16}$ Recommendations of the task force on BP control in children. Pediatrics 1977;59(suppl 1):802-3.

17 Dickinson CJ, Lawrence JR. A slowly developing pressor response to small concentrations of angiotensin. Its bearing on the pathogenesis of chronic renal hypertension. Lancet 1963;ii:1354-6.

${ }^{18}$ Hostetter TH, Olson JL, Renne HG, et al. Hyperfiltration in remnant nephrons: a potentially adverse response to renal ablation. Am J Physiol 1981;241:85-93.

${ }^{19}$ Shimamura T, Morrison AB. A progressive glomerulosclerosis occurring in partial five-sixths nephrectomized rats. Am J Pathol 1975;79:95-101.

21) Kotchen TA, Kotchen JM, Guthrie GP, Cottrill CM. Plasma renin activity, reactivity, concentration and substrate following hypertension during pregnancy. Effect of oral contraceptive agents. Hypertension 1979;1:355-61.

Correspondence to Dr M J Dillon, Hospital for Sick Children, Great Ormond Street, London WC1N 3JH, England.

Reccived 10 February 1987 